\title{
Sequential Path Analysis for Determination of Relationship Between Yield and Yield Components in Bread Wheat (Triticum aestivum L.)
}

\author{
Mohtasham MOHAMMADI ${ }^{1 *}$, Peyman SHARIFI ${ }^{2}$, Rahmatollah KARIMIZADEH ${ }^{1}$ \\ ${ }^{1}$ Dryland Agricultural Research Institute, Gachsaran, Iran; mobtashammohammadi@yahoo.com ("corresponding author) \\ ${ }^{2}$ Department of Agronomy and Plant Breeding, Rasht Branch, Islamic Azad University, Rasht, Iran
}

\begin{abstract}
An experiment was conducted to evaluate 295 wheat genotypes in Alpha-Lattice design with two replications. The arithmetic mean and standard deviation of grain yield was 2706 and $950(\mathrm{~kg} / \mathrm{ha})$, respectively. The results of correlation coefficients indicated that grain yield had significant and positive association with plant height, spike length, early growth vigor and agronomic score. Whereas there were negative correlation coefficients between grain yield and days to physiological maturity and canopy temperature before and during anthesis. Path analysis indicated agronomic score and plant height had high positive direct effects on grain yield, while canopy temperature before and during anthesis, and days to maturity, wes another trait having negative direct effect on grain yield. The results of sequential path analysis showed the traits that accounted as a criteria variable for high grain yield were agronomic score, plant height, canopy temperature, spike length, chlorophyll content and early growth vigor, which were determined as first, second and third order variables and had strong effects on grain yield via one or more paths. More important, as canopy temperature, agronomic score and early growth vigor can be evaluated quickly and easily, these traits may be used for evaluation of large populations
\end{abstract}

Keywords: canopy temperature, chlorophyll content, dryland, selection

Abbreviation: grain yield (GYD), thousand kernel weight (TKW), days to heading (DHE), days to physiological maturity (DMA), plant height (PLH), chlorophyll content (CC), spike length (SL), canopy temperature 10 day before anthesis $\left(\mathrm{CT}_{\mathrm{BA}}\right)$, canopy temperature at anthesis $\left(\mathrm{CT}_{\mathrm{AA}}\right)$, leaf waxiness (WAX), early growth vigor (EGV) and agronomic score (AS).

\section{Introduction}

Grain yield in wheat is the results of a number of complex morphological and physiological processes affecting each other and occurring on different growing stage of vegetation period. It was proposed that grain yield is contingent upon the number of spikes per unit area, the number of kernels per spike and the average kernel weight (Poehlman, 1994).

Studying the relationships between grain yield and yield components can be carried out by simple correlation and path analysis. Simple correlation was used to study the relationship between grain yield and yield component traits by some of researchers. Ghaderi et al. (2009) indicated a significant positive association between grain yield and harvest index, biological yield, the number of spike per square meter. Leilah and AlKhateeb (2005) revealed that plant height, number of spikes per square meter, 100-grain weight, weight of grains per spike, harvest index and biological yield had significant positive correlation with grain yield. Kandic et al. (2009) found highly significant correlations between grain yield and early vigor and total biomass per plant.
Simple correlation analysis is not able to provide factual cognizance between response and predictor variables, therefore, path analysis was used in the most cases and effect associations. This method which allows studying complex relationships between traits developed by Wright (1921) as a statistical tool and organizes the affect and presents the causal relationships between predictor and response variables by path diagram. In the most path analysis studies, researchers considered complete traits as the first-order variable to analyze their effects on a dependent or response variable such as grain yield. This approach leads to multi-colliniarity for predictor variables, and there may be difficulties in explaining the real contribution of each variable (Hair et al., 1995). To prevent this mistake explanation, researchers applied a sequential path analysis to determine the relationship between yield and yield components traits in wheat (Leilah and Al-Khateeb, 2005), rice (Samonte et al., 2006), maize (Mohammadi et al., 2003) and sorghum (Maman et al., 2004). Leilah and Al-Khateeb (2005) indicated five wheat variables including weight of grain per spike, harvest index, biological yield, number of spikes per square meter and 
lastly spike length accepted to be limiting in grain yield prediction. Taleei and Bahramnejad (2003) showed that for obtaining maximum grain yield, direct effect belongs to vegetative growth rate and harvest index. Kandic et al. (2009) revealed early growth vigor, early maturity and leaf senescence were found to be suitable for wheat breeding under different moisture regimes. Khan et al. (2010) indicated that peduncle length had the highest direct effect on grain yield followed by tillers per square meter, grains per spike, spike length and days to maturity, whereas peduncle extrusion, sheath length, 1000 grain weight and plant height had negative direct effect on grain yield.

This study was carried out to determine direct and indirect effects of bread wheat yield components on grain yield and to estimate correlations between grain yield and the other studied traits.

\section{Materials and methods}

\section{Field experiments}

This experiment was conducted to evaluate 295 wheat genotypes in an Alpha-Lattice design with two replications at subtropical Gachsaran Dryland Agricultural Research Station (Southwest of Iran) during (2009-2010) under dry land condition. Each plot consisted in two rows of $2.5 \mathrm{~m}$ long and $25 \mathrm{~cm}$ between the rows. Plants were fertilized with nitrogen at the rate of $80 \mathrm{~kg} / \mathrm{ha}$ urea and phosphorus at the rate of $120 \mathrm{~kg} / \mathrm{ha}$ ammonium phosphate. The same fertilizer was used in all alpha-lattice plots. All plots were hand weeded as necessary to maintain proper weed control and protect against the pests. All recommended agronomic practices were followed raise a good crop. The estimated traits were early growth vigor (EGV), days to heading (DHE), days to physiological maturity (DMA), plant height (PLH), spike length (SL), canopy temperature 10 day before anthesis $\left(\mathrm{CT}_{\mathrm{BA}}\right)$, canopy temperature at anthesis $\left(\mathrm{CT}_{\mathrm{AA}}\right)$, chlorophyll content (CC) leaf waxiness (WAX), and agronomic score (AS), grain yield (GYD), and thousand kernel weight (TKW).

Canopy temperature was measured using a hand-held infrared thermometer (Model LT-300, Sixth sense). Measurements were taken with the infrared thermometer held approximately $30 \mathrm{~cm}$ above the canopy at a 30 angle from the horizon, between 12 and $15 \mathrm{~h}$. Leaf chlorophyll content was determined at 50\% anthesis using a self calibrating chlorophyll meter (Minolta SPAD model 502) in arbitrar absorbance or SPAD units. Five flag leaves from five random plants were measured and averaged in each plot.

\section{Statistical analysis}

Pearson correlation coefficients between various pairs of the characters were computed by SPSS 17.0. The significance probability level for data analysis was 5\%. Sequential stepwise multiple regressions were conducted to organize the predictor variables into the first, second and third-order paths based on their respective contributions to the total variation of respective variable (GY) and minimum collinearity. The level of multicollinearity in each component path was measured from two common measures, namely the tolerance $\left(1-R_{i}^{2}\right)$ and its inverse the variance inflation factor $[\mathrm{VIF}=1$ / $\left(1-R_{i}^{2}\right)$ ] as suggested by Hair et al. (1995). Tolerance value is the amount of variability of the selected independent variable not explained by other independent variables. Where, $R_{i}^{2}$ is the coefficient of determination for the prediction of variable $i$ by the predictor variables. Variance inflation factor (VIF) indicates the extent of effects of other independent variables on the variance of the selected independent variable $\left[\mathrm{VIF}=1 /\left(1-R_{i}^{2}\right)\right.$ ] (Mohammadi et al., 2003). Very small tolerance values (much below 0.1 ) or large variance inflation factor (above 10) indicate a high collinearity.

Direct effects of the yield characters were estimated by the procedure described by Williams et al. (1990). Partial coefficient of determination (analogues to $\mathrm{R}^{2}$ of linear regression) was calculated from the path coefficients for grain yield, agronomic score, plant height and spike length.

\section{Results}

Tab. 1 showed the minimal and maximal values, average and standard deviation for all estimated traits of wheat genotypes. The arithmetic mean and standard deviation of grain yield were 2706 and $950 \mathrm{~kg} / \mathrm{ha}$. The minimum and maximum values of grain yield were also 340 and $6630 \mathrm{~kg} / \mathrm{ha}$.

The data referring to Tab. 3 showed AS, $\mathrm{CT}_{\mathrm{AA}}$, TKW, PLH, $\mathrm{CT}_{\mathrm{BA}}$ and DMA as first order predictor variables for response variable (grain yield).

The agronomic score and plant height had high positive direct effects on grain yield, while canopy

Tab. 1. Basis statistics (minimum and maximum values, arithmetic mean and standard deviation (SD) for the estimated variables of wheat

\begin{tabular}{ccccccccccccc}
\hline Parameters & $\begin{array}{c}\text { GYD } \\
(\mathrm{kg} / \mathrm{ha})\end{array}$ & $\begin{array}{c}\text { TKW } \\
(\mathrm{g})\end{array}$ & $\begin{array}{c}\text { DMA } \\
(\text { day })\end{array}$ & $\begin{array}{c}\text { PLH } \\
(\mathrm{cm})\end{array}$ & $\begin{array}{c}\text { CC } \\
(\text { SPAD })\end{array}$ & $\begin{array}{c}\text { SL } \\
(\mathrm{cm})\end{array}$ & $\begin{array}{c}\text { CTB } \\
(\mathrm{C})\end{array}$ & $\begin{array}{c}\text { CTA } \\
(\mathrm{C})\end{array}$ & $\begin{array}{c}\text { WAX } \\
(1-5)\end{array}$ & $\begin{array}{c}\text { EGV } \\
(1-5)\end{array}$ & $\begin{array}{c}\text { AS } \\
(1-5)\end{array}$ \\
Min & 340 & 17 & 93 & 52 & 49.3 & 10.5 & 22.8 & 22.8 & 1 & 2 & 1 & 5 \\
Max & 6630 & 38 & 129 & 106 & 50.9 & 9.6 & 21.7 & 21.9 & 4 & 5 & 5 \\
Average & 2706 & 25 & 121 & 76 & 49.2 & 9.8 & 20.5 & 21.8 & 4 & 4 & 4 \\
SD & 950 & 2.71 & 3.45 & 9.32 & 3.03 & 2.08 & 1.96 & 2.01 & 0.97 & 1.032 & 1.10 \\
\hline
\end{tabular}

GYD: grain yield; TKW: thousand kernel weight; DMA: days to physiological maturity; PLH: plant height; CC: chlorophyll content; SL: spike length; CTB: canopy temperature 10 day before anthesis; CTA: canopy temperature at anthesis; WAX: leaf waxy; EGV: early growth vigor; AS: agronomic score 
Tab. 3. Direct and indirect effects of first order predictor variables on grain yield of wheat varieties

\begin{tabular}{cccccccc}
\hline Traits & AS & CTA & TKW & PLH & CTB & DMA & Overall effects \\
AS & $\underline{0.463}$ & -0.177 & 0.010 & 0.304 & -0.227 & -0.043 & 0.726 \\
CTA & 0.078 & $\underline{-0.205}$ & -0.007 & 0.044 & -0.094 & 0.024 & -0.481 \\
TKW & -0.003 & -0.005 & $\underline{-0.144}$ & -0.028 & -0.021 & -0.020 & -0.153 \\
PLH & 0.094 & -0.031 & 0.029 & $\underline{0.143}$ & -0.028 & -0.012 & 0.507 \\
CTB & 0.082 & -0.077 & -0.024 & 0.032 & $\underline{-0.168}$ & 0.034 & -0.515 \\
DMA & 0.011 & 0.014 & -0.017 & 0.010 & $\underline{-0.024}$ & $\underline{-0.117}$ & -0.133 \\
& \multicolumn{2}{c}{$\mathrm{R}^{2}=0.63$} & & & & \\
\hline
\end{tabular}

TKW: thousand kernel weight; DMA: days to physiological maturity; PLH: plant height; CTB: canopy temperature 10 day before anthesis; CTA: canopy temperature at anthesis; AS: agronomic score.

temperature 10 day before anthesis, days to physiological maturity, canopy temperature at anthesis and thousand kernel weights were other traits having negative direct effect on grain yield (Tab. 3 and Fig. 1). These six traits explained $63 \%$ of the total variation for grain yield, this means that the most of variation in grain yield was explained by the traits included in the model. There were positive indirect effects of $\mathrm{AS}$ on grain yield via $\mathrm{CT}_{\mathrm{AA}}$, PLH, $\mathrm{CT}_{\mathrm{BA}}$ and DMA. Plant height positive had indirect effects on grain yield via $\mathrm{AS}, \mathrm{CT}_{\mathrm{AA}}, \mathrm{CT}_{\mathrm{BA}}$ and DMA. The strongest overall effect (positive in each case) on grain yield was detected for AS $(p=0.726)$. The above mentioned traits appeared as the most important indirect yield contributing traits because they indicated substantial positive indirect effects towards grain yield.

The procedure of path analysis was again performed separately taking AS and PLH as dependent variables to discover the first order variables for these two response variables, which will be the second-order variables for grain yield. Results of this procedure revealed PLH, $\mathrm{CT}_{\mathrm{BA}}, \mathrm{DMA}, \mathrm{CC}$ and $\mathrm{CT}_{\mathrm{AA}}$ as predictor variables for agronomic score as dependent variable. These five variables were as second order variable for grain yield. The direct effects of PLH and CC were positive on AS and consequently influenced grain yield of studied wheat varieties. The path analysis of second-order variables showed that $60 \%$ of total variation for AS was explained by traits that were included in the model (Tab. 4 and Fig. 1). Plant height had the highest positive direct effect on AS $(p=0.547)$.

Plant height was determined by direct effect of SL,

Tab. 5. Direct and indirect effects of second order predictor variables on grain yield by plant height as response variable

\begin{tabular}{ccccc}
\hline Traits & SL & EGV & CTA & $\begin{array}{c}\text { Overall } \\
\text { effects }\end{array}$ \\
SL & $\underline{0.380}$ & 0.134 & 0.001 & 0.503 \\
EGV & 0.124 & $\underline{0.352}$ & 0.028 & 0.466 \\
CTA & -0.001 & -0.020 & $\underline{-0.250}$ & -0.221 \\
& $\sqrt{1-R^{2}}=0.77$ & & \multicolumn{2}{c}{$\mathrm{R}^{2}=0.41$} \\
\hline
\end{tabular}

SL: spike length; CTA: canopy temperature at anthesis; EGV: early growth vigor
EGV and $\mathrm{CT}_{\mathrm{AA}}$ as first-order variables and the Adjusted R Square was 41\% (Tab. 5). SL and EGV were positive and directly influenced PLH, whereas $\mathrm{CT}_{\mathrm{AA}}$ had negative direct effect on PLH. The highest direct effect was recorded for SL $(p=0.38)$. The indirect effects of SL and EGV on grain yield were also positive via each other. Results of path analyses when spike length was used as response variables indicated PLH, EGV and TKW as first-order predictor variables, which will be the thirdorder variables for grain yield, and accounted only $28 \%$ of observed variation in SL (Tab. 6). The indirect effects of these three traits on spike length were also positive via one another. For this response, the variable PLH had highest positive direct effect on SL ( $p=0.407)$.

\section{Discussion}

The degree of symmetrical relationships between two variables was estimated by correlation coefficient and this coefficient helps to understand the nature and the importance of relation between yield and yield components. The results of correlation coefficients (Tab. 2) indicated grain yield exhibited significant and positive connection with plant height, spike length, early growth vigor and agronomic score. Whereas, correlation coefficients between GYD and the other studied traits (TKW, DMA, $C T_{\mathrm{BA}}$ and $\mathrm{CT}_{\mathrm{AA}}$ ) were significant and negative. Thousand kernel weight exhibited positive association with DMA, PLH, CC, SL and CT $_{\mathrm{BA}}$. Plant height had also positive correlation with TKW, SL and grain yield. This indicated that taller genotypes not only tended to have taller and heavier spikes but also had

Tab. 6. Direct and indirect effects of third order predictor variables on grain yield by spike length as response variable

\begin{tabular}{clllc}
\hline Traits & PLH & EGV & TKW & $\begin{array}{c}\text { Overall } \\
\text { effects }\end{array}$ \\
PLH & $\underline{0.407}$ & 0.189 & 0.081 & 0.503 \\
EGV & 0.070 & $\underline{0.150}$ & 0.013 & 0.352 \\
TKW & 0.025 & 0.011 & $\underline{0.129}$ & 0.223 \\
& $\sqrt{1-R^{2}}=0.84$ & \multicolumn{2}{c}{$\mathrm{R}^{2}=0.28$} \\
\hline
\end{tabular}

TKW: thousand kernel weight; PLH: plant height; EGV: early growth vigor 
Tab. 4. Direct and indirect effects of second order predictor variables on grain yield by agronomic score as response variable

\begin{tabular}{cccccccc}
\hline Traits & PLH & CTB & DMA & CC & CTA & Overall effects \\
PLH & $\underline{0.547}$ & -0.105 & -0.045 & -0.001 & -0.119 & 0.655 \\
CTB & 0.072 & $\underline{-0.378}$ & 0.077 & -0.056 & -0.174 & -0.491 \\
DMA & 0.011 & 0.028 & $\underline{-0.136}$ & 0.001 & 0.016 & -0.092 \\
CC & 0.001 & 0.015 & -0.001 & $\underline{0.099}$ & 0.003 & 0.041 \\
CTA & 0.024 & -0.051 & 0.013 & -0.004 & $\underline{-0.108}$ & -0.383 \\
& & $\mathrm{R}^{2}=0.60$ & & & $\sqrt{1-R^{2}}=0.63$ \\
\hline
\end{tabular}

DMA: days to physiological maturity; PLH: plant height; CC: chlorophyll content; CTB: canopy temperature 10 day before anthesis; CTA: canopy temperature at anthesis.

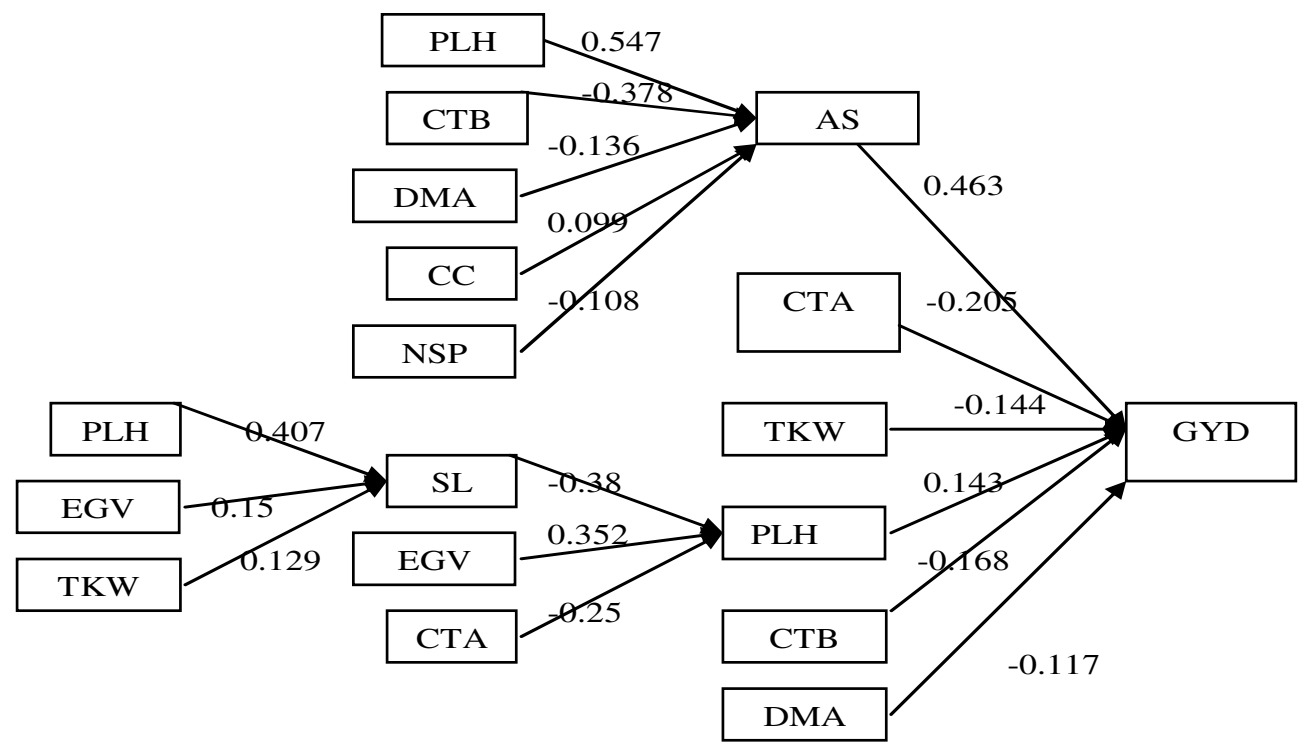

Fig. 1. Sequential path model indicating the interrelationships among grain yield whit related traits. GYD: grain yield; TKW: thousand kernel weight; DMA: days to physiological maturity; PLH: plant height; CC: chlorophyll content; SL: spike length; CTB: canopy temperature 10 day before anthesis; CTA: canopy temperature at anthesis; WAX: leaf waxy; EGV: early growth vigor; AS: agronomic score

Tab. 2. Simple correlation coefficients $(r)$ for the estimated eleven variables of wheat

\begin{tabular}{|c|c|c|c|c|c|c|c|c|c|c|c|}
\hline Traits & GYD & TKW & DMA & PLH & $\mathrm{CC}$ & SL & CTB & CTA & WAX & EGV & AS \\
\hline GYD & 1 & $-0.153^{* *}$ & $-0.133^{*}$ & $0.506^{* *}$ & 0.025 & $0.160^{* *}$ & $-0.513^{* *}$ & $-0.483^{* *}$ & 0.074 & $0.127^{*}$ & $0.727^{* *}$ \\
\hline TKW & & 1 & $0.142^{\circ}$ & $0.198^{* *}$ & $0.180^{* \prime}$ & $0.225^{*}$ & $0.143^{\circ}$ & 0.031 & 0.057 & 0.089 & 0.022 \\
\hline DMA & & & 1 & -0.083 & 0.000 & -0.016 & $-0.203^{* *}$ & $-0.119^{*}$ & $-0.222^{* *}$ & $-0.138^{*}$ & -0.092 \\
\hline PLH & & & & 1 & 0.002 & $0.503^{* *}$ & $-0.193^{* *}$ & $-0.220^{* *}$ & 0.106 & $0.465^{* \prime}$ & $0.655^{* \prime}$ \\
\hline CC & & & & & 1 & -0.007 & $0.148^{*}$ & 0.035 & 0.077 & -0.062 & 0.041 \\
\hline SL & & & & & & 1 & -0.086 & 0.004 & 0.097 & $0.351^{* *}$ & $0.283^{* *}$ \\
\hline СТВ & & & & & & & 1 & $0.460^{* *}$ & -0.005 & 0.025 & $-0.490^{*}$ \\
\hline CTA & & & & & & & & 1 & -0.012 & 0.080 & $-0.384^{\circ}$ \\
\hline WAX & & & & & & & & & 1 & 0.086 & 0.083 \\
\hline EGV & & & & & & & & & & 1 & $0.223^{* *}$ \\
\hline AS & & & & & & & & & & & 1 \\
\hline
\end{tabular}

GYD: grain yield; TKW: thousand kernel weight; DMA: days to physiological maturity; PLH: plant height; CC: chlorophyll content; SL: spike length; CTB: canopy temperature 10 day before anthesis; CTA: canopy temperature at anthesis; WAX: leaf waxiness; EGV: early growth vigor; AS: agronomic score. 
123

weighty grains per spike. Days to physiological maturity revealed significant and positive association with TKW, PLH, CC, SL and $\mathrm{CT}_{\mathrm{BA}}$, indicating that wheat late maturity genotypes had also taller and heavier spikes. The correlation analysis indicated wheat grain yield had significant and positive correlation coefficients with PLH, SL, EGV and AS. The strong positive correlation of grain yield with one or more than one of the above mentioned traits has been also observed by previous researchers i.e. (Leilah and Al-Khateeb, 2005; Kandic et al., 2009; Aydin et al., 2010; Dogan, 2009).

Path coefficient analysis is one of the biometrical techniques which have been exploited to quantify the connections of different yield attributes and also their direct and indirect effects on grain yield using correlation values. According to this procedure two traits including agronomic score and plant height had high positive direct effects on grain yield as first order predictor variable. Results of sequential path analysis showed plant height and chlorophyll content had positive direct effect on grain yield as second order variable via agronomic score. Spike length and early growth vigor had positive direct effect on grain yield as second order variable by plant height as response variable. The results of path analysis were also indicated PLH, EGV and TKW, which were as third order predictor variables, had positive effect on grain yield via spike length. Although, $\mathrm{CT}_{\mathrm{AA}}$ and TKW had negative direct effect on grain yield as first order variable (It is the contribution of an effective rainfall in second part of grain filling period that caused heavier grain weight in some late maturity genotypes) and CC, SL and EGV not included in model, they had positive effect on grain yield as second and third order predictor variables. Sen and Toms (2007) indicated that 1000 grain weight and days to maturity showed direct positive effect on grain yield. Leilah and Al-Khateeb (2005) indicated weight of grain per spike and spike length to be accepted in wheat grain yield prediction. Khan et al. (2010) indicated that spike length influenced the grain yield of wheat. Jahanbin et al, (2011) indicated plant height had the most positive direct effect on wheat grain yield. Since CT has been shown to be well associated with ability to extract water from depth (Reynolds et al., 2005) selection for CT is most probably increasing gene frequencies for root-related traits.

Difficulty of selection for improved adaptation to abiotic stresses makes the use of indirect measures attractive to plant breeders. A good example is canopy temperature, for which measurement is quick (10 seconds), easy (aim and pull the trigger) and inexpensive. Previous studies have shown strong association between yield and canopy temperature (CT) under drought, indicating the potential of the trait as an indirect selection criterion for achieving genetic gains in drought adaptation (Reynolds et al., 2000; Balota et al., 2008).

The direction of correlation coefficient of causal factors (agronomic score and plant height) and the effect (grain yield) were same with their direct effects, suggesting true relationship and direct selection through this trait will be effective (Singh and Chaudhary, 1979). In general, it is logical to conclude that agronomic score and plant height were the major contributors towards grain yield since these two traits had high correlation and also high direct effect with grain yield, thus direct selection for these two traits should be major concern for wheat plant breeder. The negative direct effects of TKW, in combination with their positive effects through other paths, indicating that selection based on correlations alone or by application of all of the traits as first order variables may not be efficient. This means the efficiency of sequential path analysis for detecting cause and effect connections.

\section{Conclusions}

In conclusion, the traits that accounted as a criteria variable for high grain yield were agronomic score, plant height, canopy temperature, spike length, chlorophyll content and early growth vigor, which were determined as first, second and third order variables and had strong effects on grain yield via one or more paths. Traits such as agronomic score, plant height was as first order variable and had also positive correlation and direct effect on grain yield, so that they may be used as suitable selection criteria. Moreover, spike length, chlorophyll content and early growth vigor were as second order variable and thousand kernel weight were as third order variables. More important, as canopy temperature, agronomic score and early growth vigor can be evaluated quickly and easily, these traits may be used for evaluation of large populations.

\section{References}

Aydin N, Ermet C, Mut Z, Bayramo HO, Özcan H (2010). Path analyses of yield and some agronomic and quality traits of bread wheat (Triticum aestivum L.) under different environments. African J Bio 9(32):5131-5134.

Balota M, Payne WA, Evett SR, Peters TR (2008). Morphological and Physiological Traits Associated with Canopy Temperature Depression in Three Closely Related Wheat Lines. Crop Sci 48:1897-1910.

Dogan, R (2009). The Correlation and path analysis for yield and some of yield components of durum wheat (Triticum turgidum var. durum) in west Anatolia conditions. Pak J Bot 41(3):1081-1089.

Ghaderi MG, Zeialikhanghah H, Hosseinzade AH, Taleei AR, Naghavi MR (2009). Evaluation of relationships between grain yield, yield components and the other characteristics associated with grain yield in bread wheat using multivariate statistical analysis. Iranian J Crop Res 7(2):573-582 (In Persian).

Hair JR, Anderson RE, Tatham RL, Black WC (1995). Multivariate Data Analysis with Readings. Prentice Hall. Englewood.

Jahanbin M, Roshdi M, Zaefizadeh M (2011). Effect of End Season Drought Stress on Yield and its Components in Synthetic Wheat. Middle.-East J Sci Res 9(3):330-333.

Kandic V, Dodig, D, Jovic M, Nikolic B, Prodanovic S (2009). The importance of physiological traits in wheat breeding under irrigation and drought stress. Genetika 41(1):11-20.

Khan AJ, Azam F, Ali A (2010). Relationship of 
morphological traits and grain yield in recombination inbred with lines grown under drought conditions. Pak J Bot 42(1):259-267.

Leilah AA, Al-Khateeb SA (2005). Statistical analysis of wheat yield under drought conditions. J Arid Env 61:483-496.

Maman N, Mason SC, Lyon DJ, Dhungana P (2004). Yield components of pearl millet and grain sorghum across environments in the central Great Plains. Crop Sci 44:2138-2145.

Mohammadi SA, Prassana, BM, Singh NN (2003). Sequential path model for determining interrelationships among grain yield and related characters in maize. Crop Sci 43:16901697.

Reynolds MP, Mujeeb-Kazi A, Sawkins M (2005). Prospects for utilising plant-adaptive mechanisms to improve wheat and other crops in drought and salinity-prone environments. Annals Appl Biotechn 146(2):239-259.

Reynolds M, Skowmand B, Trethowan R (2000). Evaluating a conceptual model for drought tolerance. In: Ribaut JM, Poland D (Eds.). Molecular approaches for the genetic improvement of cereals for stable production in waterlimited environments. A strategic planning workshop held at CIMMYT, El Batan, Mexico, 21-25 June 1999. CIMMYT, Mexico p. 49-53.
Poehlman JM (1994). Breeding Field Crops. Third Ed. Iowa State University Press.

Samonte SB, Wilson TL, Tabien RE (2006). Maximum node production rate and main culm node number contributions to yield and yield-related traits in rice. Field Crops Res 96:313-319.

Sen C, Toms B (2007). Character association and component analysis in wheat (Triticum aestivum L.). Crop Res (Hisar) 34:166-170.

Singh RK, Chaudhary BD (1979). Boimetrical methods in quantitative genetic analysis, Kalyani Publisher Ludhiana p. 304.

Taleei A, Bahramnejad BA (2003). Study of Relationship Between Yield and Its Components in Landrace Populations of Wheat from Western Parts of Iran Using Multivariate Analysis. Iranian J Agric Sci 34(4):949-959 (In Persian).

Williams WA, Jones MB, Demment MW (1990). A concise table for path analysis statistics. Agronomy Journal 82:1022-1024.

Wright S (1921). Correlation and causation. J Agric Res 20:557-585. 